\title{
BALANÇO DE CARBOIDRATOS EM GEMAS FLORAIS DE DOIS GENÓTIPOS DE PEREIRA SOB CONDIÇÃO DE INVERNO AMENO ${ }^{1}$
}

\author{
ALEXANDRE COUTO RODRIGUES ${ }^{2}$, FLÁVIO GILBERTO HERTER ${ }^{3}$, VALTAIR VERÍSSIMO ${ }^{4}$, \\ ÂNGELA DINIZ CAMPOS ${ }^{3}$, GABRIEL BERENHAUSER LEITE ${ }^{5}$, JOÃO BAPTISTA DA SILVA ${ }^{6}$
}

\begin{abstract}
RESUMO - As pereiras européias e asiáticas, cultivadas sob condições de inverno ameno, como na região Sul do Brasil, apresentam problemas de adaptação. Durante o inverno, as oscilações térmicas e o baixo acúmulo de frio têm sido referidos por alguns autores como causas do abortamento de gemas florais. O objetivo deste trabalho foi determinar o balanço de carboidratos em tecidos de gemas florais de duas cultivares de pereiras: Kieffer (P. communis x P. pyrifolia) e Housui (P. pyrifolia). Os tecidos de gemas florais e da base de gemas foram coletados mensalmente, de fevereiro a setembro de 2002, de plantas de pomar da Embrapa Clima Temperado, Pelotas-RS, coordenadas $32^{\circ} 51^{\prime} \mathrm{S}$ e $52^{\circ} 21^{\prime} \mathrm{O}$, localizado a 230 metros de altitude. O material vegetal foi analisado separadamente quanto às concentrações de açúcares solúveis (por cromatografia gasosa) e porcentagens de amido (por espectrofotometria). Em ambas as cultivares, observou-se que a base da gema é um importante local de reserva. Ocorreram significativos aumentos de açúcares solúveis nas gemas das duas cultivares na fase que antecede a brotação. Em setembro, os açúcares solúveis totais na matéria seca (MS), nas gemas florais da cv. Housui $\left(38,33 \mathrm{mg} \mathrm{g}^{-1}\right)$, foram menores do que os observados nos tecidos da cv. Kieffer (50,39 mg g-1), cultivar melhor adaptada às condições climáticas. O açúcar-álcool sorbitol, seguido da sacarose, foi o açúcar solúvel mais abundante nos tecidos das duas cultivares.
\end{abstract}

Termos para Indexação: Pyrus sp., açúcares solúveis, sorbitol, sacarose, amido, abortamento floral.

\section{BALANCE OF CARBOHYDRATES IN FLOWER BUD OF TWO PEAR TREE GENOTYPES UNDER MILD WINTER CONDITIONS}

\begin{abstract}
Most of the European and Asian pear cultivars, when cultivated under mild winter such as in Southern of Brazil, have adaptation problems. The temperature oscillations during the winter and the little chilling hours accumulation have been considered by some researchers as causes of flower bud abortion. The purpose of this study was to determine the levels of carbohydrates in tissues of flower buds of the two pear cultivars: Kieffer (P. communis x P. pyrifolia) and Housui (P. pyrifolia). Flower bud and its surrounding base tissues (bud cushion) were monthly collected since February until September 2002, from pear trees in a orchard of Embrapa Temperate Climate Research Center ( $32^{\circ} 51^{\prime}$ S and $52^{\circ} 21^{\prime} \mathrm{W}$ ), located at $230 \mathrm{~m}$ of altitude. The tissues of the flower buds and bud cushion were separately analysed for soluble sugars concentration (by GLC) and starch percentage (by spectrophotometry), in the Laboratory of Plant Physiology of Embrapa. It was observed that the bud cushion tissue is an important site of starch accumulation on both cultivars. There were marked increases in soluble sugars in the flower bud tissues of both cultivars, previously to budbreak. However the total soluble sugars accumulation in the buds of cv. Housui, in September ( $38,33 \mathrm{mg} \mathrm{g}^{-1} \mathrm{DW}$ dry weight), were lower than those of cv. Kieffer $\left(50,39 \mathrm{mg} \mathrm{g}^{-1} \mathrm{DW}\right)$, which has better adaptation. Sorbitol followed by sucrose was the more abundant water soluble sugar in both tissues of the two cultivars.
\end{abstract}

Index terms: Pyrus sp., soluble sugars, sorbitol, sucrose, starch, flower bud abortion.

\section{INTRODUÇÃO}

As plantas frutíferas de clima temperado apresentam o fenômeno da dormência. Nesse período, durante o inverno, ocorre a conversão do amido para açúcares solúveis, como substrato para a retomada de crescimento na primavera. O amido é o mais importante carboidrato de reserva nas plantas. No inverno, essas reservas amiláceas são parcialmente convertidas em açúcares solúveis dentro das partes aéreas e das raízes finas. Nas plantas frutíferas de clima temperado, as reservas são essencialmente utilizadas na primavera (Lacoite et al., 1993). A mobilização dos açúcares solúveis está diretamente ligada aos eventos climáticos, principalmente à temperatura, e tem grande importância nos estudos de adaptação de frutíferas de clima temperado. No Brasil, o estudo da mobilização dos carboidratos está sendo utilizado para compreender os problemas decorrentes da falta de frio hibernal, em frutíferas de clima temperado (Herter et al., 2001).

A maioria das cultivares de pereiras produtoras de frutas de alta qualidade não tem boa adaptação às condições climáticas da região Sul do Brasil, principalmente, devido ao frio hibernal insuficiente para a satisfação da dormência (Petri et al., 2001). Disso, resulta brotação errática e deficiente, floração desuniforme com baixo número de flores, afetando negativamente a produtividade. Oscilações térmicas durante o inverno e baixo acúmulo de frio têm sido referidos como causa do abortamento de gemas florais (Herter et al., 2001). Nas cultivares de pereira mais exigente, o problema de abortamento ou necrose de primórdios atinge índices que, em algumas cultivares, inviabiliza a exploração econômica. Em geral, o abortamento é menos severo nas áreas mais frias, como São Joaquim-SC e Vacaria-RS.

Uma das hipóteses para a ocorrência do abortamento floral, é que os períodos com temperaturas relativamente altas durante o período de repouso das plantas (sem atividade fotossintética), poderiam provocar o aumento da taxa respiratória e exaurir as reservas de carboidratos em níveis insatisfatórios para suprir as necessidades das gemas florais para a retomada do crescimento e subseqüente floração, frutificação e emissão dos novos brotos da estação de crescimento (Gardin, 2002).

O presente trabalho teve como objetivo determinar os níveis dos carboidratos, no período de fevereiro a setembro, em gemas florais de duas cultivares de pereira, cultivadas em condições de inverno ameno.

\section{MATERIALE MÉTODOS}

O experimento foi realizado na Embrapa Clima Temperado, em Pelotas-RS, no laboratório de Fisiologia Vegetal, em 2002. Utilizaram-se

\footnotetext{
${ }^{1}$ (Trabalho 182/2005). Recebido: 07/11/2005. Aceito para publicação: 23/03/2006.

${ }^{2}$ Eng $^{\text {o }}$. Agr ${ }^{\circ}$, Dr., Pesquisador RD/CNPq, Embrapa Clima Temperado, Br 392, Km 78, Cx. Postal 403, 96001-970, Pelotas-RS, Correio eletrônico: rcale@ufpel.edu.br. ${ }^{3}$ Eng $^{\mathrm{O}}$. Agr ${ }^{\mathrm{o}}$, Dr., Pesquisador, Embrapa Clima Temperado, Br 392, Km 78, Cx. Postal 403, 96001-970, Pelotas-RS, Correio eletrônico: herter@cpact.embrapa.br. ${ }^{4} \mathrm{Eng}^{\circ}$. Agr ${ }^{\circ}$, Doutorando UFPEL/ FAEM, Dpto. Fitotecnia - Fruticultura, Cx. Postal 354, CEP 96001-015, Pelotas-RS.

${ }^{5} \mathrm{Eng}^{\circ}$. Agr ${ }^{\circ}$, Dr., Pesquisador, EPAGRI - Caçador-SC.

${ }^{6}$ Eng $^{\circ}$. Agr ${ }^{\circ}$, Dr., Livre docente, Prof. Titular IFM-UFPEL, Pelotas-RS.

Apoio financeiro: CNPq, Embrapa Clima Temperado e JICA.
} 
plantas de pereiras de duas cultivares, pertencentes à coleção instalada na Estação Experimental da Cascata, localizada nas coordenadas $32^{\circ}$ $51^{\prime} \mathrm{S}$ e $52^{\circ} 21^{\prime} \mathrm{W}$ e altitude de $230 \mathrm{~m}$. A cultivar Kieffer (P. communis $x P$. pyrifolia) apresenta reduzido índice de abortamento, e a cultivar Housui (P. pyrifolia) apresenta problemas de adaptação e altos índices de abortamento quando crescidas em região de inverno ameno.

As coletas e análises de gemas florais e bases das gemas foram realizadas mensalmente, em ramos do ano, dos quatro quadrantes de cada planta, desde o final de fevereiro até o final de setembro. As gemas coletadas desses ramos, juntamente com seu tecido basal adjacente (base da gema), foram imediatamente imersas em nitrogênio líquido, no campo, para inativação enzimática e posterior liofilização em laboratório. Por meio da metodologia descrita por Rodrigues et al. (2005), analisou-se por cromatografia gasosa, nas gemas e bases das gemas, a concentração (mg $\mathrm{g}^{-1} \mathrm{MS}$ ) de açúcares solúveis (frutose, glicose, sorbitol, sacarose), em 500 $\mathrm{mg}$ de matéria seca (liofilizada). Posteriormente, determinou-se a percentagem de amido por espectrofotometria, utilizando-se de $100 \mathrm{mg}$ de peso seco do precipitado utilizado na extração dos açúcares solúveis. Para a quantificação do amido, procedeu-se de acordo com o método Starch Assay Kit (Amylase/Amyloglucosidase Method) Kit STA-20, da marca SIGMA, e fez-se a leitura da absorbância a $540 \mathrm{~nm}$, em espectrofotômetro Shimadzu UV-1601 PC.

$\mathrm{O}$ delineamento experimental utilizado foi o inteiramente casualizado, com três repetições, sendo a unidade experimental constituída por uma planta, num arranjo fatorial $\mathrm{AxBxC}$, sendo as cvs. Housui e Kieffer (A), gema e base da gema (B), em parcelas, e época de coleta $(C)$ em subparcelas. Realizaram-se a análise de variação e a comparação entre as médias pelo teste Duncan $(\alpha=0,05)$. Todas as análises foram realizadas pelo programa SANEST (Zonta \& Machado, 1991).

\section{RESULTADOS E DISCUSSÃO}

A partir dos resultados, observaram-se variações nos teores de carboidratos analisados, tanto nos tecidos vegetais quanto na época de coleta.

Em ambas as cultivares, o nível de amido foi maior no tecido da base da gema do que na gema, em todas as épocas de coleta (Fig. 1 e 2), sendo um importante local de acúmulo de amido. Em pessegueiro, Bonhomme (1998), comparando os teores de amido na gema e no ramo, também obteve maiores teores no ramo comparado àqueles obtidos nas gemas, em todas as épocas estudadas.

Observou-se na cultivar Housui reserva reduzida de amido na gema (Fig. 2) e, tendo a gema a necessidade de proteger seus tecidos contra o frio invernal, no período de ocorrência das menores temperaturas, essa demandou maior degradação de amido da base durante o inverno (Julho), o que refletiu na acumulação de açúcares solúveis nos tecidos da gema e base da gema (Fig. 2). Por outro lado, a cv. Kieffer não teve similar degradação do amido na base da gema (Fig. 1), isso porque já possuía alta concentração de açúcares solúveis para serem translocados, e maior nível de amido na gema, que, posteriormente, na retomada de crescimento, em agosto, se converteu em açúcares solúveis. Isto pode ser um indicativo de que a cv. Kieffer, que necessita de menor acúmulo de frio, está mais adaptada.

As plantas da cv. Kieffer requerem muito menos acúmulo de frio e têm melhor adaptação nas condições climáticas de inverno de Pelotas. As plantas da cv. Kieffer necessitam de 300 horas de frio ( $\leq$ $7,2^{\circ} \mathrm{C}$ ) e têm apresentado menores índices de abortamento floral, enquanto a cv. Housui necessita de 720 horas de frio $\left(\leq 7,2^{\circ} \mathrm{C}\right)$ e tem tido baixa adaptação nessa região. A acumulação de frio no inverno de 2002 foi de 396 horas $\left(\leq 7,2^{\circ} \mathrm{C}\right)$.

A maior porcentagem de amido nas gemas da cv. Kieffer em relação à cv. Housui, a partir de junho (Fig. 1 e 2), é algo a ser considerado quanto ao abortamento floral. Justamente nos meses que antecedem a brotação, a cv. Kieffer encontra-se com mais reserva energética. Já a cv. Housui se apresenta com maior esgotamento de reservas, possivelmente devido à manutenção de altas taxas respiratórias.

De acordo com Sauter \& Kloth (1987), o amido é degradado pela ação de fosforilases e amilases. Quando são necessárias grandes quantidades de glicose, esta degradação ocorre essencialmente por intermédio das amilases. Tal degradação tem importância na resistência ao frio, sendo que esse processo de transformação é fortemente controlado pelas temperaturas. Segundo Yoshioka et al. (1988), no inverno, aumenta a atividade da amilase, sacarose-6-P-sintase e sacarose-sintase nos tecidos do lenho e da casca, convertendo amido em glicose, frutose e sacarose. Esses carboidratos solúveis possuem uma função importante na resistência ao frio, bem como prover energia e substratos para o crescimento inicial dos ramos na primavera.

Possivelmente, a degradação do amido esteja ligada à síntese

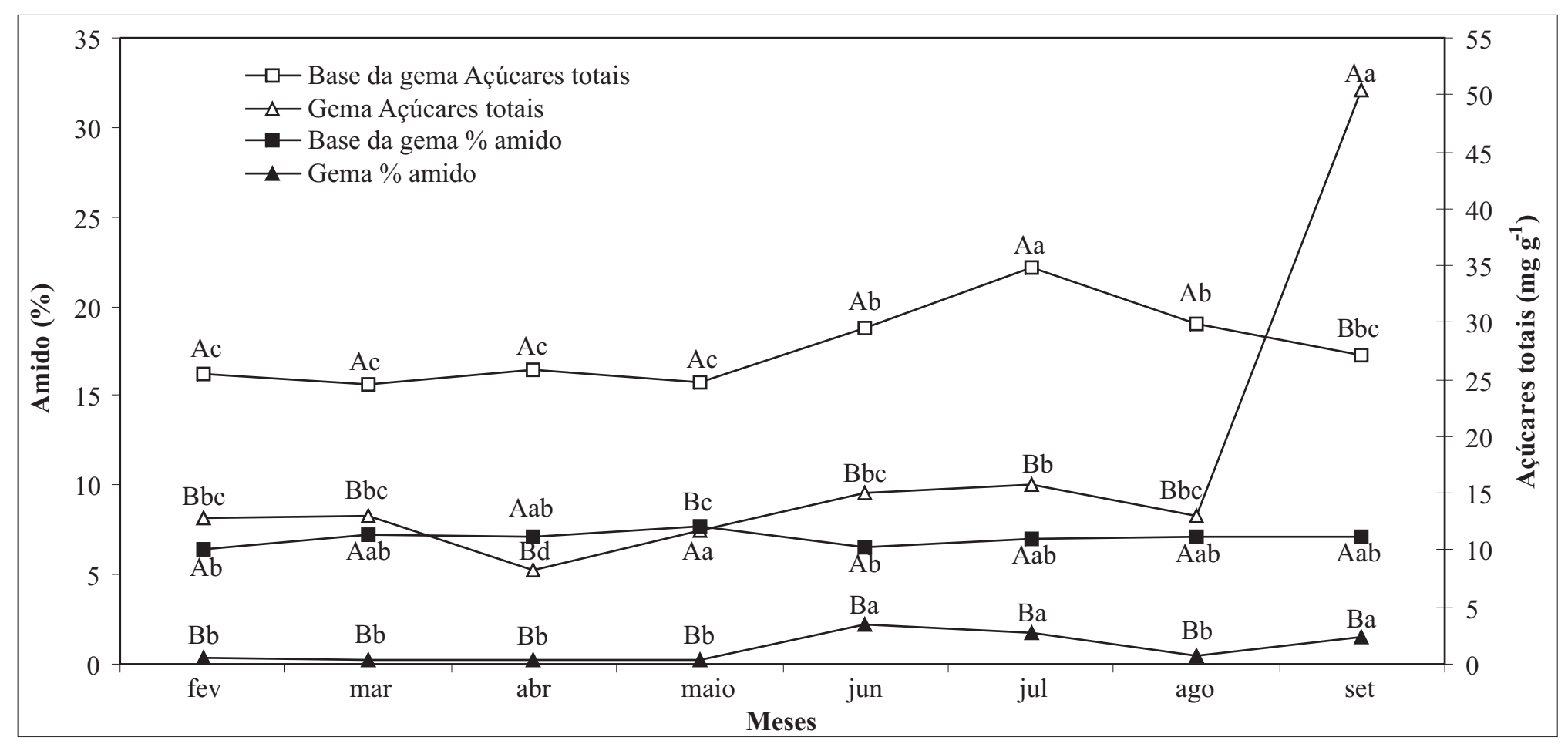

FIGURA 1 - Níveis de amido (\%) e açúcares solúveis totais ( $\left.\mathrm{mg} \mathrm{g}^{-1}\right)$, na gema e base da gema da cultivar Kieffer, de fevereiro a setembro, em PelotasRS, 2002. Embrapa Clima Temperado, Pelotas-RS. Médias seguidas pela mesma letra, maiúscula para tipo de tecido vegetal e época de coleta, e minúsculas na linha, não diferem estatisticamente, pelo teste Duncan (á=0,05). 


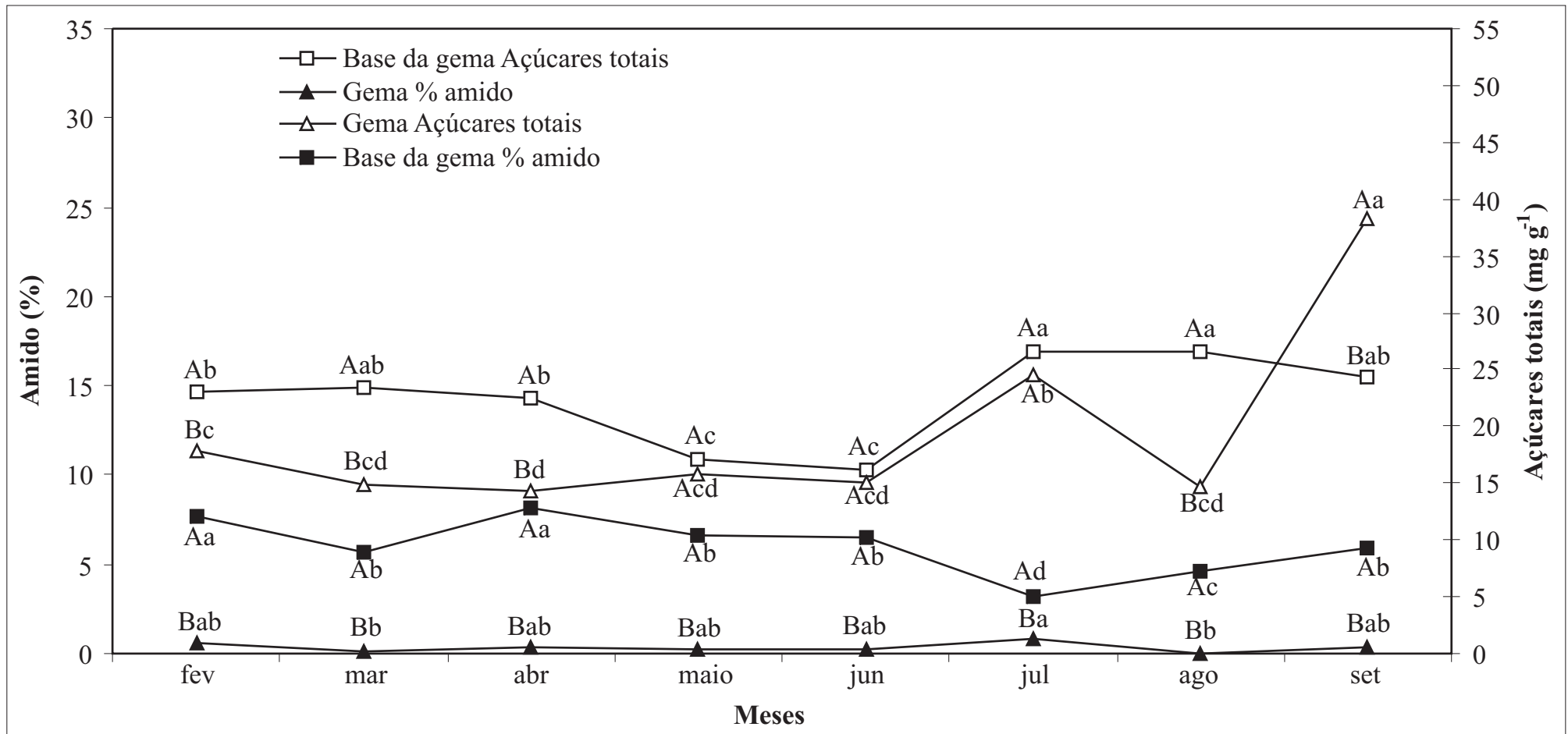

FIGURA 2 - Níveis de amido (\%) e açúcares solúveis totais $\left(\mathrm{mg} \mathrm{g}^{-1}\right)$, na gema e base da gema da cultivar Housui, de fevereiro a setembro, em PelotasRS, 2002. Embrapa Clima Temperado, Pelotas-RS. Médias seguidas pela mesma letra, maiúscula para tipo de tecido vegetal e época de coleta, e minúsculas na linha, não diferem estatisticamente, pelo teste Duncan (á $=0,05)$.

de carboidratos solúveis durante o repouso (Gardin, 2002; Yoshioka et al., 1988). Segundo Rakngan (1995), o conteúdo de amido em pereiras asiáticas aumenta durante o período de crescimento vegetativo e decresce durante o inverno, aumentando o conteúdo de açúcares. Desta forma, justifica-se a diminuição de amido nas gemas no mês de agosto, nas cvs. Housui e Kieffer (Fig.1 e 2), época precedida pelas menores temperaturas do ano, no início de julho (Fig. 5), seguido do aumento de temperatura no mês de agosto e a subseqüente saída da dormência. Segundo Gardin (2002), a redução no conteúdo de amido pode ser causada pela mobilização de fotoassimilados das fontes para os drenos.

Houve importante aumento nos açúcares solúveis, nos tecidos das gemas florais de ambas as cultivares, previamente à brotação (Fig. 1 e 2); resultados semelhantes também foram observados por Gardin

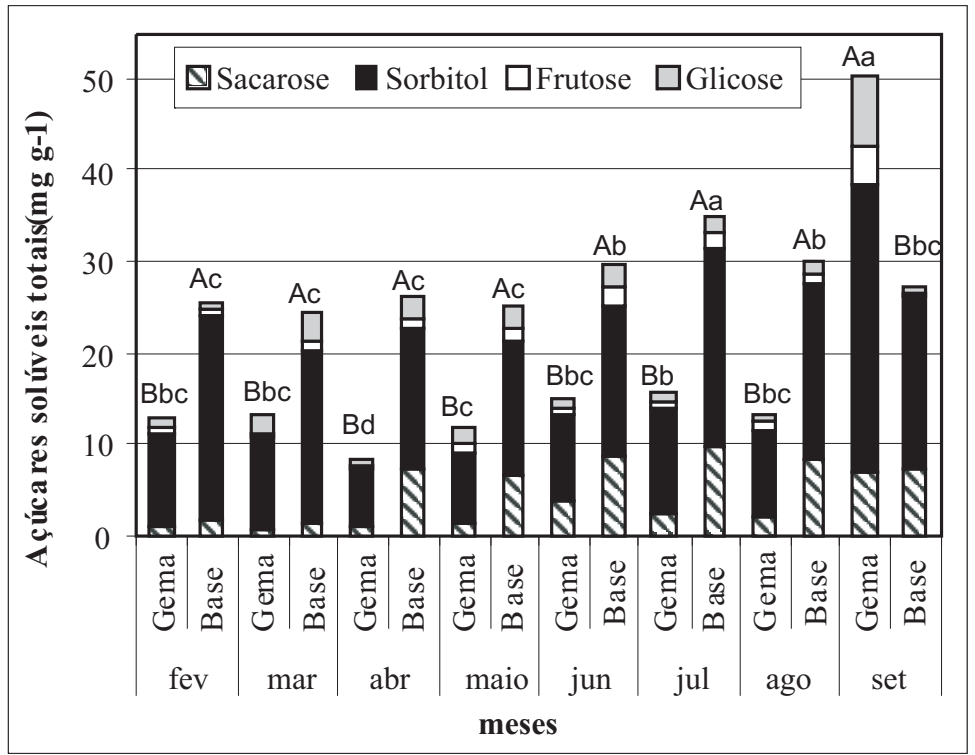

FIGURA 3 - Teores de açúcares solúveis $\left(\mathrm{mg} \mathrm{g}^{-1}\right)$ em gema e base da gema, na cv. Kieffer, de fevereiro a setembro de 2002. Embrapa Clima Temperado, Pelotas-RS. Médias seguidas pela mesma letra, maiúscula entre tecidos, e minúscula para cada época, não diferem estatisticamente, pelo teste de Duncan $(\alpha=0,05)$.
(2002). Entretanto, a acumulação de açúcares solúveis totais nas gemas de cv. Housui, em setembro (38,33 $\mathrm{mg} \mathrm{g}^{-1} \mathrm{MS}$ - Matéria Seca), foi menor que na cv. Kieffer (50,39 $\left.\mathrm{mg} \mathrm{g}^{-1} \mathrm{MS}\right)$. Esse aumento nos açúcares solúveis, no final do inverno, deve-se, em parte, à translocação destes açúcares da base para a gema, a fim de desenvolver a estrutura floral.

A menor concentração de açúcares solúveis nos tecidos da base da gema na cv. Housui (Fig. 2), durante maio e junho, pode ter sido devida à translocação desses compostos para as gemas, em função da temperatura durante o período (Fig. 5). Flutuações térmicas e altas temperaturas têm influência no metabolismo de carboidratos e, conseqüentemente, na adaptação das cultivares.

Em ambos os tecidos, das duas cultivares (Fig. 3 e 4), o sorbitol, seguido da sacarose, foi o açúcar solúvel mais expressivo na dinâmica

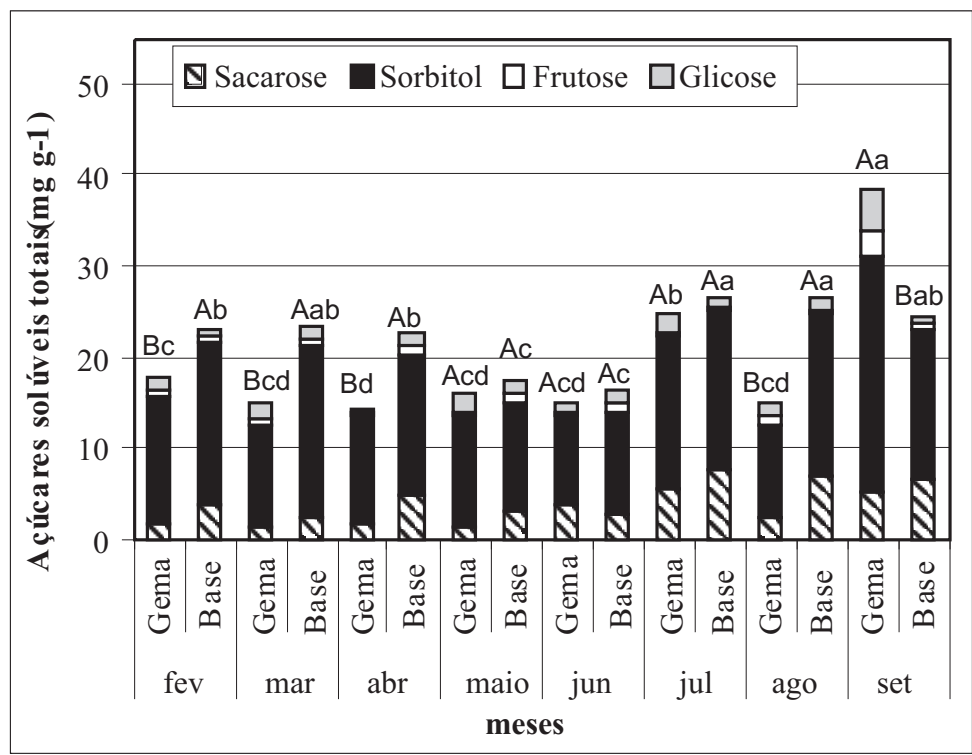

FIGURA 4 - Teores de açúcares solúveis $\left(\mathrm{mg} \mathrm{g}^{-1}\right)$ em gema e base da gema, na cv. Housui, de fevereiro a setembro de 2002. Embrapa Clima Temperado, Pelotas-RS. Médias seguidas pela mesma letra, maiúscula entre tecidos, e minúscula para cada época, não diferem estatisticamente, pelo teste de Duncan $(\alpha=0,05)$. 


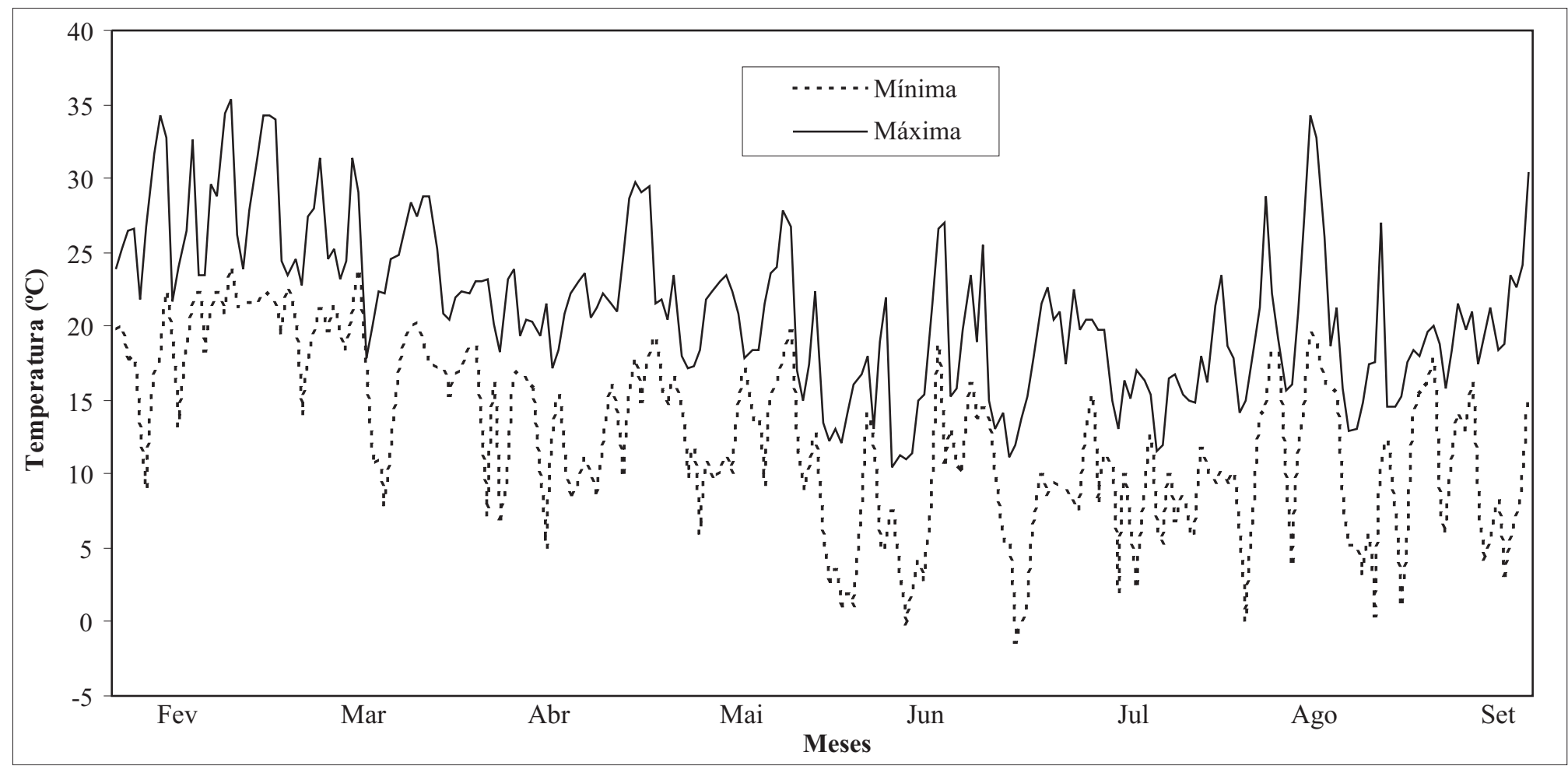

FIGURA 5 - Temperaturas máximas e mínimas diárias, de fevereiro a setembro de 2002, obtidas na Estação Agrometeorológica. Embrapa Clima Temperado, Pelotas-RS.

dos carboidratos solúveis, nas pereiras em estudo, concordando com os resultados de Gardin (2002). De acordo com Rakngan (1995), em gemas de pereira (Pyrus pyrifolia), o sorbitol é o açúcar mais abundante, seguido da glicose, frutose e sacarose.

O sorbitol pode ser formado a partir da redução da glicose, frutose ou sorbose e exerce importante função de transporte, sendo a principal função proteger os tecidos contra a desidratação, a salinidade e a resistência ao frio (Loescher \& Everard, 1996; Loescher, 1987; Bieleski, 1982), caracterizando-se também como um carboidrato de reserva.

Em plantas da família Rosaceae, à qual pertence a pereira, a sacarose é encontrada na seiva do floema, porém o sorbitol aparece em maior quantidade, sendo o mais importante produto da fotossíntese (Salisbury \& Ross, 1992; Loescher \& Everard, 1996).

\section{CONCLUSÕES}

1. A base das gemas é um importante local de reserva em plantas de pereira das cvs. Kieffer e Housui.

2. Na fase que antecede a brotação, ocorreu significativo aumento de açúcares solúveis nas gemas das duas cultivares.

3. Em setembro, os açúcares solúveis totais na matéria seca, nas gemas florais da cv. Housui, foram menores do que os observados na cv. Kieffer, cultivar melhor adaptada às condições climáticas.

4. O sorbitol, seguido pela sacarose, foi o açúcar mais abundante em ambos os tecidos das duas cultivares de pereira.

\section{REFERÊNCIAS}

BIELESKI, R.L. Sugar alcohols. In: LOEWUS, F.A.; TANNER, W. (Eds.). Plant carbohydrates. I. Intracellular carbohydrates. Encyclopedia Plant Physiol. New Ser. Berlin: Springer-Verlag, 1982. v.13A, p.158192.

BONHOMME, M. Physiologie des bourgeons végétatifs et floraux de Pêcher dans deux situations thermiques contrastées pendant la dormance: capacité de croissance, force de puits et repartition des glucides. 1998. 547f. Tese (Doutorado em Fisiologia Vegetal) Université Blaise Pascal, Clermont Ferrand.

GARDIN, J.P.P. Abortamento de gemas florais e níveis de carboidratos em gemas e ramos de pereira, cultivar Nijisseiki, no outono e inverno. 2002. 32f. Dissertação (Mestrado Fisiologia Vegetal) Instituto de Biologia, Universidade Federal de Pelotas, Pelotas, 2002.

HERTER, F.G.; VERÍSSIMO, V.; CAMELATTO, D.; GARDIN, J.P.; TREVISAN, R. Abortamento de gemas florais de pereira no Brasil. In: SEMINÁRIO SOBRE FRUTICULTURA DE CLIMA TEMPERADO, 1., 2001, Florianópolis. Anais... p.106-114.

LACOINTE, A.; KAJJI, A.; DAUDET, F.; PHILIPPE, A.; FROSSARD, J. Mobilization of carbon reserves in young walnut trees. Acta Botanic Gallica, Cedex, v.140. n.4, p.435-441, 1993.

LOESCHER, W.H.; EVERARD, J.D. Sugar alcohol metabolism in sinks and sources. In: ZAMSKI, E.; SCHAFFER, A.A. (Ed.) Photoassimilate distribution in plants and crops: source-sink relationships. New York: Marcel Dekker, 1996. p.185-207.

LOESCHER, W.H. Physiology and metabolism of sugar alcohols in higher plants. Physiology Plantarum, Copenhagem, v.70, p.553$557,1987$.

PETRI, J.L.; LEITE, G.B.; FAORO, I.D. Tratos culturais. In: EPAGRI. Nashi: a pêra japonesa. Florianópolis: Epagri/Jica, 2001. cap.7, p.195210.

RAKNGAN, J. Carbohydrate analysis of Japanese pear trees grown under adverse conditions. In: Phenological and physiological study of Japanese pear grown under adverse condition. Tsukuba, 1995. cap.3, p.61-63.

RODRIGUES, A.C.; HERTER, F.G.; VERÍSSIMO, V.; CHAVARRIA, G.; GARDIN, J.P.P.; CAMPOS, A.D. Determinação por cromatografia gasosa de açúcares solúveis em frutíferas de clima temperado. Revista Brasileira de Fruticultura, Jaboticabal, v.27, n.1, p.173$174,2005$.

SALISBURY, F.B.; ROSS, C.W. Plant Physiology. $4^{\text {th }}$ ed. California: Wadsworth Publishing Company, 1992. 682p.

SAUTER, J.J.; KLOTH, S. Changes in carboydrates and ultrastruture in xylem ray cells of Populus in response to chiling. Protoplasma, Vienna, n.137, p.45-55, 1987.

YOSHIOKA, H.; NAGAI, K.; AOBA, K.; FUKUMOTO, M. Seasonal changes of carbohydrates metabolism in apple trees. Scientia Horticulturae, Amsterdan, n.36, p.219-227, 1988.

ZONTA, E.P.; MACHADO, A.A. Manual do SANEST: sistema de análise estatística para microcomputadores. Pelotas: UFPEL, 1991. 102p. 